\title{
Treatment Concepts for Restoration of endodontically Treated Teeth: A Survey among General Practitioners, Prosthodontists, and Endodontists in India
}

\author{
${ }^{1}$ Aditya A Kavlekar, ${ }^{2}$ Meena A Aras, ${ }^{3}$ Vidya Chitre
}

\section{ABSTRACT}

Aim: To study the treatment concepts for restoration of endodontically treated teeth (ETT) among general practitioners, prosthodontists, and endodontists in India and to compare practices followed by practitioners in India with that of other countries.

Materials and methods: A questionnaire consisting of 16 multiple choice questions was formulated. It was handed out randomly to general practitioners, prosthodontists, and endodontists at respective national conferences by personal handouts. The questionnaire consisted of 16 multiple choice questions that focused on the treatment philosophies of post-endodontic restoration, materials, and techniques used.

Results: $70.7 \%$ general practitioners believe that a post reinforces ETT and reduces fracture probability and they placed posts more frequently as compared to prosthodontists and endodontists. $44.6 \%$ endodontists believed that ferrule does not increase the fracture resistance. Cast post and cores were preferred by $83.2 \%$ endodontists, whereas prefabricated posts were preferred by $78.4 \%$ general practitioners. Prosthodontists used cast posts and cores as well as prefabricated posts with relatively same frequency. $70.3 \%$ endodontists, $74.1 \%$ general practitioners, and $46.3 \%$ prosthodontists preferred tapered posts. $76.2 \%$ endodontists seal root filling after post space preparation, whereas $77.7 \%$ prosthodontists and $79.3 \%$ general practitioners do not seal the root filling. $81 \%$ prosthodontists and $74.1 \%$ general practitioners reported endodontic failure as the most frequent cause of failure, however, $79.2 \%$ endodontists reported loss of retention of posts.

Conclusion: Within the limitations of the present study, there were differences in knowledge and practices followed in restoration of ETT among the different specialties - prosthodontists, endodontists, and general practitioners studied in India and also when compared to other countries.

Keyword: Endodontically treated teeth, Post and core, Survey.

How to cite this article: Kavlekar AA, Aras MA, Chitre V. Treatment Concepts for Restoration of endodontically Treated Teeth: A Survey among General Practitioners, Prosthodontists, and Endodontists in India. J Contemp Dent 2016;6(2):129-136.

\footnotetext{
${ }^{1}$ Postgraduate, ${ }^{2}$ Professor and Head, ${ }^{3}$ Professor

${ }^{1-3}$ Department of Prosthodontics, Goa Dental College and Hospital, Bambolim, Goa, India

Corresponding Author: Aditya A Kavlekar, Postgraduate Department of Prosthodontics, Goa Dental College and Hospital Bambolim, Goa, India, Phone: +918554071084, e-mail: aditya. kavlekar@ymail.com
}

\section{Source of support: Nil}

Conflict of interest: None

\section{INTRODUCTION}

The aim of Endodontic and Restorative Dentistry is to preserve the natural tooth structure and to maintain the stability of dental arch. ${ }^{1}$ Endodontic treatment is performed on teeth widely affected due to caries, fractures, or multiple restorations. Endodontically treated teeth (ETT) are weaker and more liable for fracture as there is loss of tooth structure and change in the physical characteristics. $^{2}$

Studies conducted have proven that the successful outcome of an ETT does not depend as much on the endodontic procedure as much as it depends on the postendodontic restoration. ${ }^{1}$ Post-endodontic restoration of a tooth with deficient tooth structure is often carried out by fabricating a post and core followed by a complete veneer crown. A core is a dental restoration for building up missing tooth structure for future restoration with a crown. A post is a dental material placed in the root of a structurally deficient tooth when additional retention is needed to retain the core and coronal restoration. ${ }^{1}$ Postendodontic restorations are dependent on several factors like substance loss, tooth type, whether or not intracanal anchorage is required, choice of post and core material, length and fit of endodontic post, luting medium, and type of supraconstruction., 3

Immense literature has been published with regard to knowledge and practices of post-endodontic restoration abroad; however, there is lack of such studies in India. ${ }^{5-7}$ Clinicians are left with the perplexing task of reading and compiling this information into logical and evidence-based approach to dental treatment. The available information is not clear enough to be put up as proper treatment protocol, in lieu of which clinicians rely more on their past experiences rather than on available literature. The increase in choice of materials and treatment options available for post-endodontic treatment has further added to their dilemma.

As a result, the present survey was undertaken to investigate the frequency of preferred methods, materials, timing, and other concerning factors regarding 
restorations of ETT with special emphasis on assessing the knowledge and practices used by prosthodontists, endodontists, and general practitioners in India. The present survey also allowed comparisons of beliefs and practices in restoration of ETT followed by practitioners in India with that of other countries.

\section{MATERIALS AND METHODS}

A questionnaire consisting of 16 multiple choice questions was formulated. A cover letter stated the instructions, rationale, and purpose of the survey. It was handed out randomly to general practitioners, prosthodontists, and endodontists at respective national conferences by personal handouts. The questionnaire asked for anonymous responses so as to overcome any reservation about participation.

The first part of the questionnaire consisted of general personal information of the dentist like gender, qualification, number of years of practice, and whether he/she had attended any special course for post and core.

The second part of the questionnaire consisted of 16 multiple choice questions that focused on the treatment philosophies of post-endodontic restoration, materials, and techniques used. The questions covered the following topics:

\section{Beliefs and Frequency of Use of Intracanal Posts}

The participants were asked how frequently they placed posts and their beliefs whether every ETT must receive a post, whether post reinforces ETT and reduces fracture probability, and whether a ferrule effect increases fracture resistance.

\section{Prosthetic Restoration}

The participants were questioned about frequency of use of posts depending on tooth location and restoration modalities.

\section{Materials Preferences}

The participants were questioned with regard to commonly used post system, post design, material used to construct core, and cement used to lute post.

\section{Techniques of Post Space Preparation}

Questions related to timing of post space preparation following endodontic therapy, instruments used to remove root filling material, solution used to rinse canal before cementation, and whether root filling was sealed after post space preparation were asked.

\section{Cause of Failure}

The participants were questioned regarding the cause of most frequent cause of failure of post placement.

\section{RESULTS}

\section{Demographics}

The questionnaire was answered by 116 general practitioners, 121 prosthodontists, and 101 endodontists with an overall return rate of $37 \%$. Majority of prosthodontists and endodontists were males $58.7 \%$ to $71.3 \%$ respectively; however, majority of the general practitioners were female $66.4 \% .50 .4 \%$ of prosthodontists and $52.5 \%$ endodontists had a clinical experience of 0 to 5 years, whereas $41.4 \%$ of general practitioners had a clinical experience of 5 to 10 years. A total of $69.4 \%$ of prosthodontists and $56.4 \%$ of endodontists had not attended any special course, whereas $54.3 \%$ general practitioners had undergone special courses to upgrade their skills with regard to restoration of ETT.

\section{Beliefs and Frequency of Use of Intracanal Posts}

$89.3 \%$ prosthodontists, $81.2 \%$ endodontists, and $90.5 \%$ general practitioners believed that every ETT need not receive a post (Table 1 ). $83.5 \%$ prosthodontists and $83.2 \%$ endodontists seldom place posts whereas $53.4 \%$ of general practitioners frequently placed posts in ETT. $70.7 \%$ general practitioners believe that a post definitely reinforces an ETT and reduces fracture probability whereas $68.6 \%$ prosthodontists and $80.2 \%$ endodontists believe that posts with adhesive luting reinforces an ETT and reduces fracture probability (Graph 1). 82.6\% prosthodontists and 75\% general practitioners believe that using ferrule increases fracture resistance whereas only $55.4 \%$ endodontists believe in fracture resistance effect of ferrule (Graph 2).

\section{Prosthetic Restoration}

With regard to tooth location, a more equitable frequency of post placement is seen for all tooth locations by prosthodontists, i.e., molars (26.4\%), premolars (33.9\%), and anterior teeth $(39.7 \%)$ whereas endodontists and general practitioners place posts more frequently in only premolars and anterior teeth (Table 2). $47.5 \%$ endodontists place posts more frequently in premolars whereas $48.5 \%$ place more frequently in anterior teeth. $58.6 \%$ general practitioners place posts more frequently in premolars and whereas $38.8 \%$ place more frequently in anterior teeth. $87.1 \%$ endodontists and $85.3 \%$ general practitioners use posts more frequently for single-crown therapy, whereas only $68.6 \%$ prosthodontists use posts more frequently for single-crown therapy and $21.5 \%$ prosthodontists use 
Table 1: Responses regarding beliefs and frequency of use of intracanal posts

Question

(1) Do you believe that every endodontically treated tooth must receive a post?

(2) How frequently do you place post in your dental practice?

(a) Yes

Prosthodontist Endodontist

Do you believe that a post reinforces an endodontically treated tooth and reduces fracture probability?

(b) No

10.7

(\%)

practitioner

Do you believe that reducing the level of finishing line below the core foundation, thus using a ferrule effect following

(a) Seldom (30\% of all ETT)

89.3

18.8

(\%)

(b) Frequently (30-70\% of all ETT)

83.5

81.2

9.5

(c) Usually ( $>70 \%$ of all ETT)

13.2

(a) Yes, definitely

3.3

(b) Yes, with adhesive luting

\section{1}

(c) Yes, with conventional luting

68.6

(d) No

0.8

(a) Yes

26.4

(b) No

82.6

17.4

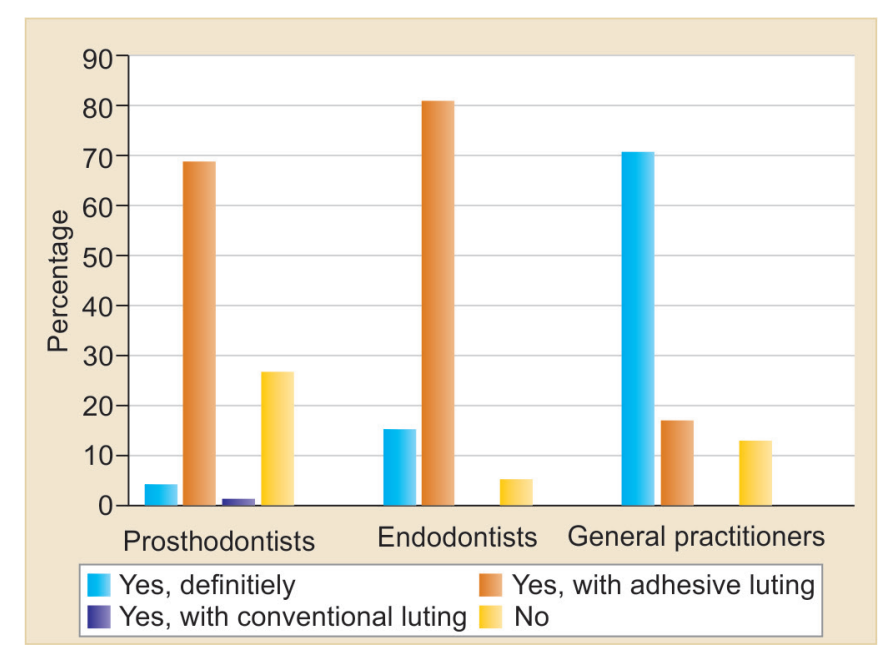

Graph 1: Comparison of responses of different dental specialties based on belief that a post reinforces an ETT and reduces fracture probability

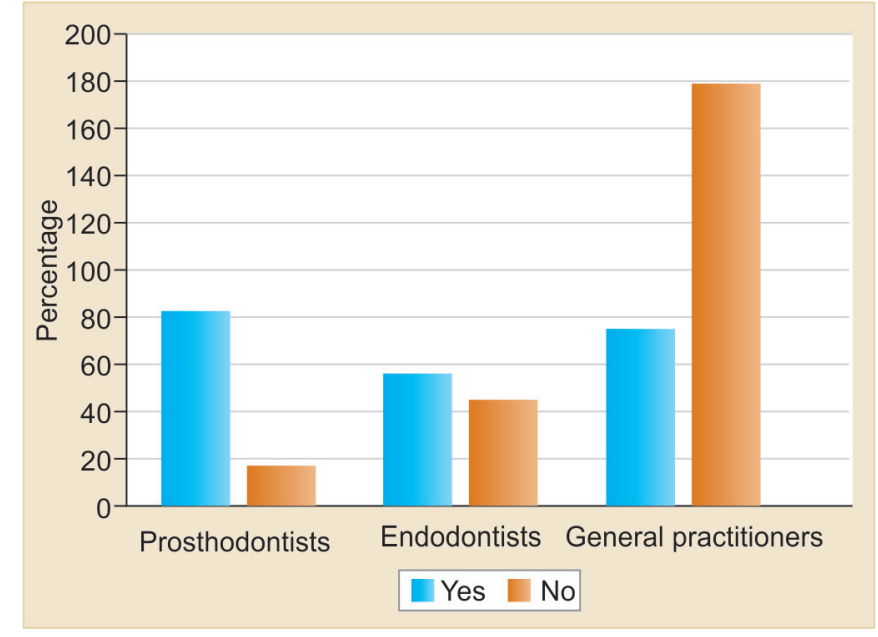

Graph 2: Comparison of responses of different dental specialties based on belief that a ferrule increases fracture resistance

Table 2: Responses regarding prosthetic restoration

\begin{tabular}{|c|c|c|c|c|}
\hline Question & Response & $\begin{array}{l}\text { Prosthodontist } \\
\text { (\%) }\end{array}$ & $\begin{array}{l}\text { Endodontist } \\
(\%)\end{array}$ & $\begin{array}{l}\text { General } \\
\text { practitioner (\%) }\end{array}$ \\
\hline \multirow{3}{*}{$\begin{array}{l}\text { (1) In which teeth do you frequently use posts } \\
\text { for restoration of endodontically treated } \\
\text { tooth? }\end{array}$} & (a) Molars & 26.4 & 4 & 2.6 \\
\hline & (b) Premolars & 33.9 & 47.5 & 58.6 \\
\hline & (c) Anteriors & 39.7 & 48.5 & 38.8 \\
\hline \multirow{3}{*}{$\begin{array}{l}\text { (2) For which of the following restoration } \\
\text { modalities do you use posts more often for } \\
\text { restoring ETT? }\end{array}$} & (a) Direct restorations & 9.9 & 1 & 6.9 \\
\hline & (b) Single-crown therapy & 68.6 & 87.1 & 85.3 \\
\hline & (c) Abutment teeth for FPD & 21.5 & 11.9 & 7.8 \\
\hline
\end{tabular}

posts more frequently to restore abutment teeth for fixed partial dentures (FPDs).

\section{Materials Preferences}

$83.2 \%$ endodontists use casts posts more frequently, however, $78.4 \%$ general practitioners place prefabricated posts more frequently whereas $52.9 \%$ prosthodontists place prefabricated posts while $47.1 \%$ place cast posts (Graph 3, Table 3). With regard to post designs, 70.3\% endodontists and $74.1 \%$ general practitioners preferred tapered posts whereas when compared to prosthodontists, $46.3 \%$ preferred tapered posts, $21.5 \%$ preferred 


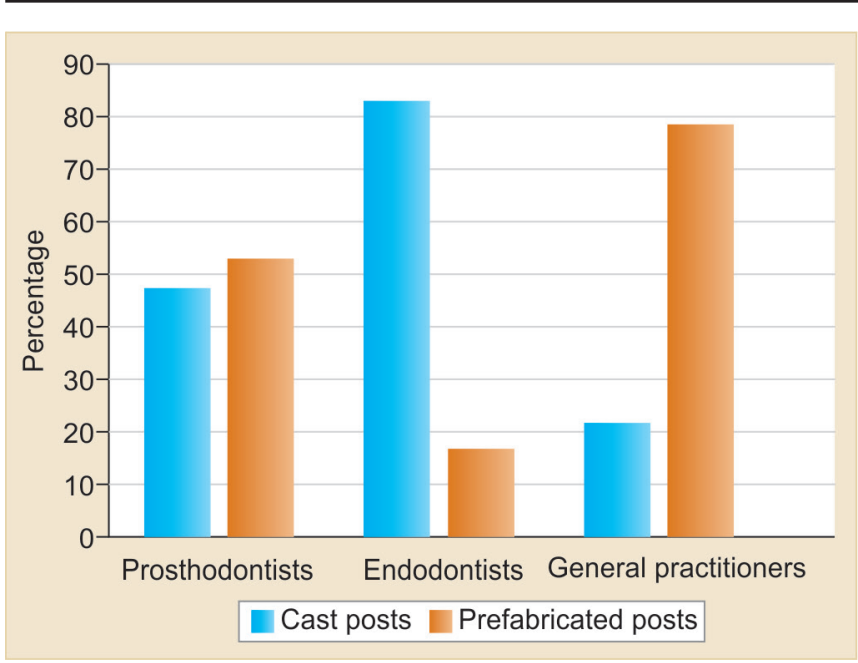

Graph 3: Comparison of responses of different dental specialties based on frequency of post system used

combined parallel sided/tapered posts, and 20.7\% preferred parallel posts. Among general practitioners, $49.1 \%$ use composite cores and $17.2 \%$ use glass ionomer cement cores on prefabricated posts more commonly. Among endodontists, $51.5 \%$ used cores other than that mentioned in the options whereas $26.7 \%$ used amalgam cores, however among prosthodontists, $30.6 \%$ used composite cores more commonly whereas $28.9 \%$ used cores other than that mentioned on the options. Among prosthodontists, $41.3 \%$ prefer glass ionomer cement, $32.2 \%$ prefer resin cement whereas $26.4 \%$ prefer zinc phosphate cement to lute the post; however, among endodontists, $37.6 \%$ prefer glass ionomer cement and $46.5 \%$ zinc phosphate cement. Among general practitioners, $56.9 \%$ prefer resin cement and $27.6 \%$ prefer glass ionomer cement.

\section{Techniques of Post Space Preparation}

$80.2 \%$ prosthodontists, $78.2 \%$ endodontists, and $81.9 \%$ general practitioners wait for 1 week after root has been filled to prepare the canal for post (Table 4). Among prosthodontists, $60.3 \%$ remove root fillings with conventional burs more frequently whereas $39.7 \%$ preferred to use special burs supplied by manufacturers whereas among endodontists, $83.2 \%$ preferred conventional burs while $16.8 \%$ preferred special burs; however, among general practitioners, $56.9 \%$ preferred special burs while $43.1 \%$ preferred conventional burs. $76.2 \%$ endodontists seal root filling after post space preparation whereas $77.7 \%$ prosthodontists and $79.3 \%$ general practitioners do not seal root filling after post space preparation. $76 \%$ prosthodontists rinse canal with distilled water, $66.3 \%$ endodontists rinse with sodium hypochlorite whereas $56 \%$ general practitioners do not rinse canal before post cementation. $69.3 \%$ endodontists and $62.9 \%$ general practitioners apply cement to post to place cement in canal whereas among prosthodontists, $38.8 \%$ apply cement to post to place cement in canal while $34.7 \%$ apply cement to canal with a lentulo spiral.

\section{Cause of Failure}

$81 \%$ prosthodontists reported endodontic failure while $12.4 \%$ reported loss of retention of post as the most frequent cause of failure (Table 5). Similarly $74.1 \%$ general practitioners reported endodontic failure while 12.9\% reported loss of retention of post as most frequent cause of failure. However, $79.2 \%$ endodontists reported loss of retention of posts while $16.8 \%$ reported endodontic failure as most frequent cause of failure (Graph 4).

Table 3: Responses regarding materials preferences

\begin{tabular}{lllll}
\hline \multirow{2}{*}{$\begin{array}{l}\text { Question } \\
\text { (1) Which post system do you use more }\end{array}$} & Response & Prosthodontist & $\begin{array}{l}\text { Endodontist } \\
\text { (\%) }\end{array}$ & $\begin{array}{l}\text { General } \\
\text { practitioner (\%) }\end{array}$ \\
frequently? & (b) Prefabricated post & 47.1 & 83.2 & 21.6 \\
(2) Which of the following post designs & (a) Tapered posts & 52.9 & 16.8 & 78.4 \\
do you prefer? & (b) Parallel posts & 46.3 & 70.3 & 74.1 \\
& (c) Combined parallel-sided/tapered & 21.5 & 1 & 17.2 \\
& (d) Screw type & 9.1 & 1 & 4.3 \\
& (e) Split flexible post & 2.5 & 0 & 2.6 \\
(3) Which material do you use more & (a) Composite & 30.6 & 13.9 & 4.7 \\
commonly to construct core on & (b) Glass ionomer cement & 18.2 & 7.9 & 17.2 \\
prefabricated post? & (c) Resin modified glass ionomer cement & 6.6 & 0 & 12.1 \\
& (d) Amalgam & 15.7 & 26.7 & 6 \\
(4) Which cement do you use to lute a & (e) If other than these (please specify) & 28.9 & 51.5 & 15.5 \\
post? & (a) Zinc phosphate cement & 26.4 & 46.5 & 15.5 \\
& (b) Glass ionomer cement & 41.3 & 37.6 & 27.6 \\
& (c) Polycarboxylate cement & 0 & 0 & 0
\end{tabular}


Table 4: Responses regarding techniques of post space preparation

\begin{tabular}{|c|c|c|c|c|}
\hline Question & Response & $\begin{array}{l}\text { Prosthodontist } \\
\text { (\%) }\end{array}$ & $\begin{array}{l}\text { Endodontist } \\
(\%)\end{array}$ & $\begin{array}{l}\text { General } \\
\text { practitioner (\%) }\end{array}$ \\
\hline \multirow{3}{*}{$\begin{array}{l}\text { (1) When do you prepare the } \\
\text { canal for post? }\end{array}$} & (a) Immediately after root has been filled & 10.7 & 19.8 & 1.7 \\
\hline & (b) Wait for 1 week after root has been filled & 80.2 & 78.2 & 81.9 \\
\hline & (c) If other than these (please specify) & 9.1 & 2 & 16.4 \\
\hline \multirow[t]{6}{*}{$\begin{array}{l}\text { (2) How do you remove the } \\
\text { root filling material? }\end{array}$} & $\begin{array}{l}\text { (a) Conventional rotary instruments, e.g., Gates } \\
\text { Glidden drills, pezoreamers }\end{array}$ & 60.3 & 83.2 & 43.1 \\
\hline & (b) Special burs supplied by manufacturers & 39.7 & 16.8 & 56.9 \\
\hline & (c) Round burs & 0 & 0 & 0 \\
\hline & (d) Hand reamers & 0 & 0 & 0 \\
\hline & (e) Heated instruments & 0 & 0 & 0 \\
\hline & (f) Solvents & 0 & 0 & 0 \\
\hline \multirow{2}{*}{$\begin{array}{l}\text { (3) Do you seal the root filling } \\
\text { after preparing the canal } \\
\text { for a post? }\end{array}$} & (a) Yes & 22.3 & 76.2 & 20.7 \\
\hline & (b) No & 77.7 & 23.8 & 79.3 \\
\hline \multirow{6}{*}{$\begin{array}{l}\text { (4) Which solution do you use } \\
\text { to rinse the canal before } \\
\text { cementing the posts? }\end{array}$} & (a) Distilled water & 76 & 30.7 & 36.2 \\
\hline & (b) Hydrogen peroxide & 5.8 & 1 & 3.4 \\
\hline & (c) Sodium hypochlorite & 9.1 & 66.3 & 2.6 \\
\hline & (d) EDTA & 2.5 & 0 & 1.7 \\
\hline & (e) Chlorhexidine & 2.5 & 0 & 0 \\
\hline & (f) Do not rinse & 4.1 & 2 & 56 \\
\hline \multirow{4}{*}{$\begin{array}{l}\text { (5) Which method do you use } \\
\text { to place the cement in } \\
\text { canal? }\end{array}$} & (a) Apply it to the post before placing in canal & 38.8 & 69.3 & 62.9 \\
\hline & (b) Applying cement to canal by probe & 19.8 & 26.7 & 23.3 \\
\hline & (c) Applying cement to canal with a lentulo spiral & 34.7 & 0 & 6.9 \\
\hline & (d) Applying cement to canal with small plastic tube & 6.6 & 4 & 6.9 \\
\hline
\end{tabular}

Table 5: Responses regarding cause of failure

\begin{tabular}{lllll}
\hline \multirow{2}{*}{ Question } & Response & Prosthodontist (\%) & Endodontist (\%) & $\begin{array}{l}\text { General } \\
\text { practitioner (\%) }\end{array}$ \\
\hline (1) Which is the most frequent failure? & (a) Loss of retention of posts & 12.4 & 79.2 & 12.9 \\
& (b) Endodontic failure & 81 & 16.8 & 74.1 \\
& (c) Crown fracture & 2.5 & 0 & 0 \\
& (d) Root fracture & 4.1 & 2 & 10.3 \\
& (e) No failures & 0 & 2 & 2.6 \\
\hline
\end{tabular}

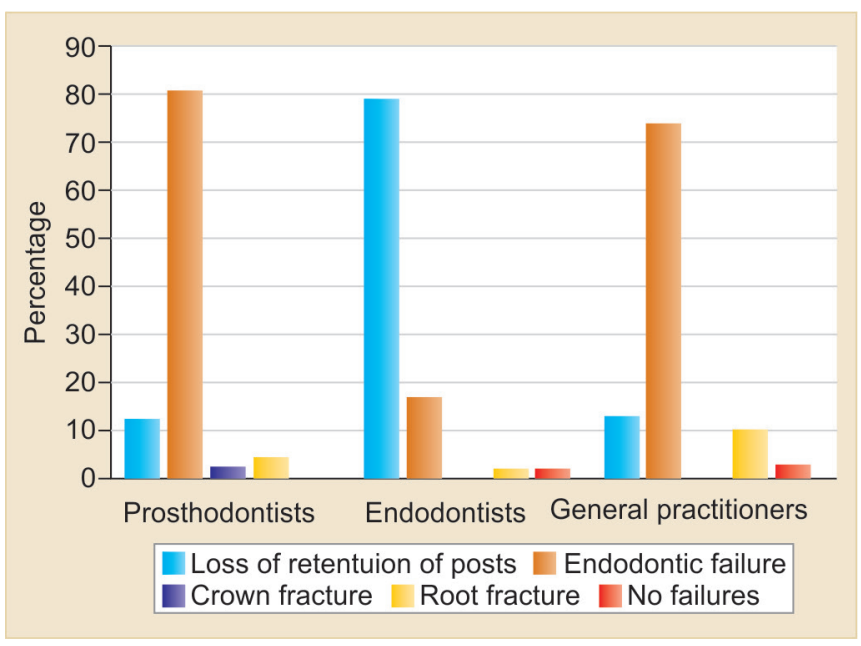

Graph 4: Comparison of responses of different dental specialties based on most frequent failure

\section{DISCUSSION}

The overall return rate of the questionnaire was $37 \%$ which is in line with other studies. ${ }^{5,6}$ Due to anonymous nature of the study, it was not possible to send reminders.
Majority of the respondents, $89.3 \%$ prosthodontists, $81.2 \%$ endodontists, and $90.5 \%$ general practitioners were not of the opinion that every ETT must receive a post which is commensurate with the consensus in the literature.

Most prosthodontists and endodontists place posts in $30 \%$ of all ETT whereas most general practitioners place posts in 30 to $70 \%$ of all ETT which is less frequent than a comparable study carried out in Germany. ${ }^{7}$

Studies have demonstrated that a post does not reinforce ETT and reduce fracture probability. ${ }^{8-12}$ Contrary to this, a large percentage of general practitioners were of the opinion that a post reinforces ETT which is much higher than studies carried out in Sweden, Germany, and United States. ${ }^{7,13,14}$ This may be the reason for majority of general practitioners placing posts frequently in ETT. However, in the present study, majority of prosthodontists $(68.6 \%)$ and endodontists $(80.2 \%)$ believed in reinforcement effect when posts were used with adhesive luting whereas in Germany, only a minority believe in reinforcement effect when post placement is performed either adhesively or conventionally. ${ }^{7}$ 
As compared to studies in Sweden, United States, and Germany, a higher percentage of prosthodontists and general practitioners believed that a reinforcement effect by using a ferrule exists which is in agreement with literature which suggests posts made with ferrule have increased resistance to failure. However, in the present study, lesser percentage of endodontists believe in fracture resistance effect of ferrule., ${ }^{713-17}$

According to literature, anterior teeth with minimal access cavity can be restored with composite resin. Premolars and molars with minimal access cavities can be restored with amalgam or composite resin in combination with a resin bonding system. Posterior teeth with large access cavities following extensive carious lesions carry greater occlusal loads and therefore require protection against possible fracture by cuspal coverage ${ }^{11,18}$ However, majority of endodontists and general practitioners place posts more frequently in premolars and anteriors. This may be due to extensive caries in these teeth or due to discoloration requiring coverage in esthetic areas. In a similar study in Sweden, it was more common to use posts in endodontically treated molars and premolars. ${ }^{13}$

Most prosthodontists, endodontists, and general practitioners use posts more commonly for single-crown therapy; however, few prosthodontists also use posts for abutment teeth for FPD. The possible explanation may be to increase the retention of crown or due to belief of reinforcement effect of posts. In the study in Sweden, the use of posts for abutments for FPDs was much more common compared to single-crown therapy. ${ }^{13}$

It was more common among endodontists to use cast posts whereas most general practitioners use prefabricated posts more frequently, which may be due to the fact that prefabricated posts are easy to use and require less chairside time. However, among prosthodontists, casts posts were used with same frequency as prefabricated posts. In Germany and UK, there was a preference for prefabricated posts, however, Swedish and British dentists preferred cast post and core. ${ }^{5,7,13,19}$ In Sweden and United States, use of cast posts was more common among prosthodontists compared to general practitioners. ${ }^{13,14}$

Endodontists and general practitioners preferred tapered posts though according to literature tapered posts have higher failure rates than both prefabricated and cast parallel-sided posts except for teeth with ovoid canals. ${ }^{20-22}$ However, among prosthodontists, most preferred tapered posts, while a minority preferred combined parallelsided/tapered posts and parallel posts. In Germany, screw-type posts were the preferred post design which was followed by tapered posts. ${ }^{7}$

Most general practitioners and prosthodontists use composite cores more frequently on prefabricated posts whereas most endodontists used cores other than that mentioned in the options in the present study. In the United States and UK, amalgam cores are more popular whereas majority of German and Swedish dentists use composite resin cores. $5,7,13,14$

Glass ionomer cement was the preferred cement to lute posts for most prosthodontists and endodontists whereas majority of general practitioners preferred resin cement. In Sweden, zinc phosphate was preferred cement among both prosthodontists and general practitioners whereas in United States and Northern Ireland, glass ionomer was preferred among general practitioners while only few prosthodontists used this cement for luting. ${ }^{13,14,19}$

Most prosthodontists, endodontists, and general practitioners preferred to wait for 1 week after root had been filled to prepare canal for posts which is comparable to a study in Northern Ireland. This result is, however, contrary to Swedish dentists who prefer to prepare the canal for posts immediately after root has been filled. ${ }^{13,19}$

Prosthodontists and endodontists preferred to remove root fillings with conventional burs which is similar to the practice followed by dentists in Sweden and United States whereas most general practitioners in the present study prefer special burs supplied by manufacturers. ${ }^{13,14}$

It has been recommended to seal the root filling after post space preparation to obtain a dense seal to prevent risk of coronal leakage which is a causal factor for root canal failure. ${ }^{23-27}$ Most endodontists seal root filling after post space preparation whereas majority of prosthodontists and general practitioners do not seal. In a comparable study in Sweden, $48 \%$ prosthodontists and $34 \%$ general practitioners practiced sealing root filling. Most commonly used material for this was zinc oxideeugenol cement. ${ }^{13}$

Rinsing of canal is recommended before post cementation to remove the smear layer formed after instrumentation of root canal. ${ }^{28}$ Most prosthodontists use distilled water, while endodontists preferred sodium hypochlorite, however most general practitioners do not rinse canal before post cementation. All prosthodontists and 92\% of general practitioners in Sweden followed this recommendation. Hydrogen peroxide + alcohol and Tubulicid (Dental therapeutics) were the commonly used rinsing solutions used by them. ${ }^{13}$

Endodontists and general practitioners preferred to apply cement to post to place cement in canal whereas among prosthodontists, $38.8 \%$ apply cement to post to place cement in canal while $34.7 \%$ apply cement to canal with a lentulo spiral. In Sweden, 32\% general practitioners applied cement to the post before placing it in the canal whereas $37 \%$ prosthodontists used a small plastic tube to perform this procedure. ${ }^{13}$

Most prosthodontists and general practitioners reported endodontic failure as the most frequent cause 
of failure, however, most endodontists reported loss of retention of posts as a cause of failure. In a study in Germany, loss of retention ( $43 \%$ ) was the most common reason for failure followed by endodontic problems (36\%) and root fractures $(29 \%){ }^{7}$

The present study exhibited variations in the knowledge and practices among clinicians in different countries and different specialties in India. The inconsistency in treatment modalities could be due to the fact that longterm studies on success rate of different restoration techniques are scarce. If long-term randomized trials are conducted in the community then a homogenous clinical trial-based dental practice will emerge. Due to contradictory responses, it is not possible to recommend a standard treatment protocol for restoration of ETT.

\section{CONCLUSION}

Within the limitations of this study, the following conclusions were drawn:

- $89.3 \%$ prosthodontists, $81.2 \%$ endodontists, and $90.5 \%$ general practitioners were not of the opinion that every ETT must receive a post.

- $70.7 \%$ general practitioners were in the false belief that a post reinforces ETT and reduces fracture probability and place posts more frequently as compared to prosthodontists and endodontists.

- $44.6 \%$ endodontists were in the false belief that ferrule does not increase the fracture resistance.

- Cast post and cores were preferred by $83.2 \%$ endodontists whereas prefabricated posts were preferred by $78.4 \%$ general practitioners. Prosthodontists used cast posts and cores as well as prefabricated posts with relatively same frequency.

- $70.3 \%$ endodontists, $74.1 \%$ general practitioners, and $46.3 \%$ prosthodontists preferred tapered posts which is contrary to the present consensus that tapered posts have a higher failure rate.

- $41.3 \%$ prosthodontists and $37.6 \%$ endodontists preferred glass ionomer cement to lute posts whereas $56.9 \%$ general practitioners preferred resin cement.

- $60.3 \%$ prosthodontists and $83.2 \%$ endodontists preferred conventional burs to remove root fillings whereas general practitioners preferred special burs supplied by manufacturers.

- $76.2 \%$ endodontists seal root filling after post space preparation whereas $77.7 \%$ prosthodontists and $79.3 \%$ general practitioners do not seal the root filling.

- $76 \%$ prosthodontists use distilled water, while $66.3 \%$ endodontists use sodium hypochlorite to rinse the canal and $56 \%$ general practitioners do not rinse canal before post cementation.

- $69.3 \%$ endodontists and $62.9 \%$ general practitioners apply cement to post to place cement in the canal whereas among prosthodontists, $38.8 \%$ apply cement to post to place cement in canal while $34.7 \%$ apply cement to canal with a lentulo spiral.

- $81 \%$ prosthodontists and $74.1 \%$ general practitioners reported endodontic failure as the most frequent cause of failure, however, $79.2 \%$ endodontists reported loss of retention of posts.

- There were difference in knowledge and practices followed in restoration of ETT among clinicians in different countries as well as between the different specialties - prosthodontists, endodontists, and general practitioners studied in India.

\section{REFERENCES}

1. Chadwick J, Gonzales A, McLean C, Naghavi A, Rosati S, Yau S. Restoration of endodontically treated teeth: An evidence based literature review. University of Toronto, Faculty of Dentistry-Community Dentistry 2008; p. 1-21.

2. Reeh ES, Messer HH, Douglas WH. Reduction in tooth stiffness as a result of endodontic restorative procedures. J Endod 1989 Nov;15(11):152-156.

3. Al-Omiri MK, Mahmoud AA, Rayyyan MR, Abu-Hammad O. Fracture resistance of teeth restored with post-retained restorations: An overview. J Endod 2010 Sep;36(9):1439-1449.

4. Biter K, Kielbassa AM. Post-endodontic restorations with adhesively luted fiber-reinforced composite post systems: A review. Am J Dent 2007 Dec;20(7):353-360.

5. Seow LL, Toh CG, Wilson NH. A survey of current practices among general dental practitioners in Manchester in 2002. Prim Dent Care 2003 Jul;10(3):87-92.

6. Brunton PA, Christensen GJ, Cheung SW, Burke FJ, Wilson NH. Contemporary dental practice in the UK: Indirect restorations and fixed prosthodontics. Br Dent J 2005 Jan;198(2):99-103.

7. Naumann M, Kiessling S, Seemann R. Treatment concepts for restoration of endodontically treated teeth: A nationwide survey of dentists in Germany. J Prosthet Dent 2006 Nov;96(5):332-338.

8. Lovdahl PE, Nicholls JI. Pin-retained amalgam cores vs castgold dowel-cores. J Prosthet Dent 1977 Nov;38(5):507-514.

9. Guzy GE, Nicholls JI. In vitro comparison of intact endodontically treated teeth with and without endo-post reinforcement. J Prosthet Dent 1979 Jul;42(1):39-44.

10. Sorensen JA, Martinoff JT. Intracoronal reinforcement and coronal coverage: A study of endodontically treated teeth. J Prosthet Dent 1984 Jun;51(6):780-784.

11. Trope M, Maltz DO, Tronstad L. Resistance to fracture of restored endodontically treated teeth. Endod Dent Traumatol 1985 Jun;1(3):108-111.

12. Assif D, Bitenski A, Pilo R, Oren E. Effect of post design on resistance to fracture of endodontically treated teeth with complete crowns. J Prosthet Dent 1993 Jan;69(1):36-40.

13. Eckerbom M, Magnusson T. Restoring endodontically treated teeth: A survey of current opinions among board-certified prosthodontists and general dental practitioners in Sweden. Int J Prosthodont 2001 May-Jun;14(3):245-249.

14. Morgano SM, Hashem AF, Fotoohi K, Rose L. A nation wide survey of contemporary philosophies and techniques of restoring endodontically treated teeth. J Prosthet Dent 1994 Sep;72(3):259-267. 
15. Gelfand M, Goldman M, Sunderland EJ. Effect of complete veneer crowns on the compressive strength of endodontically treated posterior teeth. J Prosthet Dent 1984 Nov;52(5):635-638.

16. Barkhordar RA, Radke R, Abbasi J. Effect of metal collars on resistance of endodontically treated teeth to root fracture. J Prosthet Dent 1989 Jun;61(6):676-678.

17. Isidor F, Bröndum K, Ravnholt G. The influence of post length and crown ferrule length on the resistance to cyclic loading of bovine teeth with prefabricated titanium posts. Int J Prosthodont 1999 Jan-Feb;12(1):78-82.

18. Morgano SM. Restoration of pulpless teeth: Application of traditional principles in present and future contexts. J Prosthet Dent 1996 Apr;75(4):375-380.

19. Hussey DL, Killough SA. A survey of general dental practitioners approach to the restoration of root-filled teeth. Int Endod J 1995 Mar;28(2):91-94.

20. Sorensen JA, Martinoff JT. Clinically significant factors in dowel design. J Prosthet Dent 1984 Jul;52(1):28-35.

21. Torbjörner A, Karlsson S, Ödman PA. Survival rate and failure characteristics for two post designs. J Prosthet Dent 1995 May;73(5):439-444.
22. Morgano SM, Brackett SE. Foundation restorations in fixed prosthodontics: Current knowledge and future needs. J Prosthet Dent 1999 Dec;82(6):643-657.

23. Saunders WP, Saunders EM. Coronal leakage as a cause of failure in root-canal therapy: A review. Endod Dent Traumatol 1994 Jun;10(3):105-108.

24. Beckham BM, Anderson RW, Morris CF. An evaluation of three materials as barriers to coronal microleakage in endodontically treated teeth. J Endod 1993 Aug;19(8):388-391.

25. Ray HA, Trope M. Periapical status of endodontically treated teeth in relation to the technical quality of the root filling and the coronal restoration. Int Endod J 1995 Jan;28(1):12-18.

26. Swanson K, Madison LR. An evaluation of coronal microleakage in endodontically treated teeth. Part I. Time periods. J Endod 1987 Feb;13(2):56-59.

27. Wu MK, Pehlivan Y, Kontakiotis EG, Wesselink PR. Microleakage along apical root fillings and cemented posts. J Prosthet Dent 1998 Mar;79(3):264-269.

28. McComb D, Smith DC. A preliminary scanning electron microscopic study of root canals after endodontic procedures. J Endod 1975 Jul;1(7):238-242. 